\title{
CHEMICAL PROPERTIES OF POORLY CRYSTALLINE APATITES
}

\author{
C. REY ${ }^{1}$, A. HINA ${ }^{1}$, S. SOMRANI ${ }^{2}$, M. JEMAL ${ }^{2}$, M.J. GLIMCHER ${ }^{3}$ \\ 1- Laboratoire des Matérieaux -Physico Chimie des Solides, INPT, ENSCT, ESA \\ CNRS 1543, 38 rue des 36 Ponts, 31400 Toulouse, France. \\ 2- Département de Chimie, faculté des Sciences de Tunis, 1060 Tunis, Tunisie. \\ 3- Laboratory for the Study of Skeletal Disorders and Rehabilitation, The Children's \\ Hospital, Harvard Medical School, 300 Longwood Avenue, Boston, USA.
}

\begin{abstract}
Labile environments of carbonate and $\mathrm{HPO}_{4}$ present in synthetic poorly crystalline apatites, analogous to bone mineral crystals, can be easily and reversibly exchanged. Such reactions depend on the maturation stage of the apatites and are related to both the short range order and organization of the crystals and their specific surface area. Similar reactions may also occur in bone mineral altering its properties and function as an ion reservoir in vivo.
\end{abstract}

\section{INTRODUCTION}

Poorly crystalline apatites are the major constituent of mineralized tissues of vertebrates. Their reactivity governs several biological processes such as the adsorption of mineral ions, matrix and serum proteins, adhesion of cells (example osteoclasts), and the subsequent resorption of bone. The reactivity of poorly crystalline apatites and consequently their biological functions are directly related to the structure, short range order and compositional characteristics of the crystals.

Poorly crystalline apatites contain significant amounts of carbonate and phosphate groups in non-apatitic environments which can be demonstrated by FTIR and 31-P MAS-NMR. Many of the $\mathrm{CO}_{3}{ }^{2-}$ and $\mathrm{HPO}_{4}{ }^{2-}$ groups are labile and in non-apatitic environments. These are present at higher concentrations in newly formed crystals and in the bone of young animals, and gradually diminish with time (maturation). The aim of this work was to study the role of non-apatitic labile environments in the reactivity of poorly crystalline apatites.

\section{MATERIALS AND METHODS}

Poorly crystalline apatites were prepared according to the methods published in previous papers ${ }^{1}$. Their composition was determined by chemical analysis ${ }^{1}$ of calcium, phosphate and carbonate ions. The exchange experiments were made by exposing the poorly crystalline apatites $(100 \mathrm{mg}$ ) in ammonium bicarbonate or ammonium hydrogen phosphate 1 molar $(10 \mathrm{ml})$. The samples were then centrifuged, washed with distilled water and lyophilized. The environments of mineral ions were analyzed by FTIR 
spectroscopy (Perkin Elmer 1700). The amount of non-apatitic $\mathrm{HPO}_{4}$ was determined by curve-fitting with GRAMS 386 (Galactic, NH). The dissolution enthalpy was determined as reported in previous studies 2

\section{RESULTS}

Spectroscopic techniques, applied to poorly crystalline apatites, show the existence of ionic environments of phosphate and carbonate groups that are not found in well crystallized apatites. Such groups have been qualified as "non-apatitic". At least two types of non-apatitic phosphate groups have been recognized by FTIR by an analysis of the $v_{4} \mathrm{PO}_{4}$ domain 1 . One, characterized by a band at $530 \mathrm{~cm}^{-1}$ has been assigned to a $\mathrm{HPO}_{4}{ }^{2-}$ group. The existence of this group has been confirmed by $\mathrm{NMR}^{3}$. The other group (band at $615 \mathrm{~cm}^{-1}$ ) is not so well known, but it has been observed in many poorly crystalline apatites by FTIR ${ }^{1}$. Non-apatitic carbonate species are also detected by FTIR ${ }^{4}$. They give a shoulder at $866 \mathrm{~cm}^{-1}$ in the $v_{2} \mathrm{CO}_{3}$ domain. These species have also been detected by solid state NMR spectroscopy.

When a poorly crystalline apatites is immersed in a $\mathrm{HPO}_{4}$-containing solution for a very short time $(10 \mathrm{mn})$, the number of carbonate ions decreases very markedly and the amount of $\mathrm{HPO}_{4}$ (calculated from chemical analysis) increases (Figure 1). Conversely, if a poorly crystalline apatite is immersed in a carbonate solution, the amount of carbonate increases and the $\mathrm{HPO}_{4}$ content decreases. These reactions are reversible. The amount of non-apatitic carbonate and $\mathrm{HPO}_{4}$ is determined by the composition of the solution and thus can be controlled to some extend. The environment of carbonate and hydrogenophosphate ions which are exchanged can be characterized by FTIR. The spectra (not shown) indicated that non-apatitic carbonate and non-apatitic phosphates are mainly affected by these reactions.

If we consider the difference between the carbonate uptake (in carbonate solution) and the carbonate loss (in phosphate solution), which may be considered as a measure of the extent of the reaction amplitude, we observe (Figure 2) that the exchange reaction is much greater for freshly prepared apatites, rich in non-apatitic environments, than for apatites which have matured.

In another experiment the enthalpy of dissolution of apatites matured for different times has been measured. The data obtained (Table 1) indicate that the duration of the maturation significantly modifies the enthalpy of dissolution. Freshly precipitated apatites produce less heat (about 1/3 less) than matured apatites and the differences compared with crystalline hydroxyapatites is even greater.

TABLE 1

Dissolution enthalpy of apatites at different maturation stages

\begin{tabular}{lcccccc}
\hline Maturation time & $\mathrm{O}$ & 6 hours & 24 hours & 72 hours & 9 days & 21 days \\
$\Delta \mathrm{H} \mathrm{(cal.g-1)}$ & -50.6 & -68.9 & -70.2 & -69.9 & -70.4 & -76.7 \\
\hline
\end{tabular}




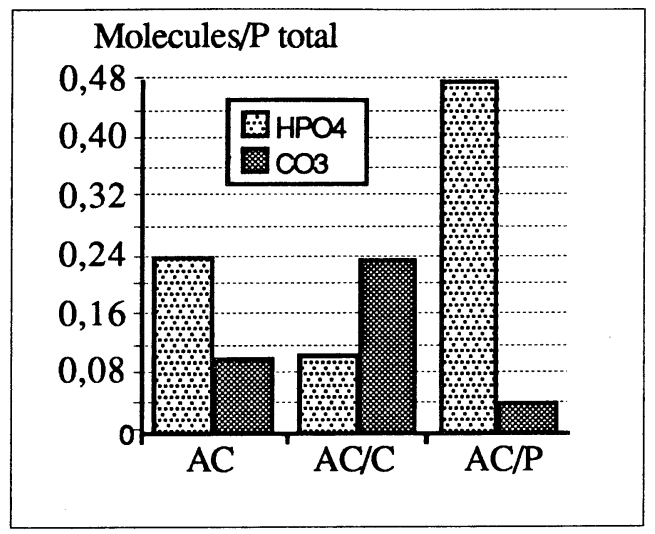

FIGURE 2: Evolution of $\mathrm{HPO}_{4}$ and $\mathrm{CO}_{3}$ content of poorly crystalline carbonated apatites, as prepared (AC), soaked in a $1 \mathrm{M}$ bicarbonate solution (AC/C), and soaked in a $1 \mathrm{M}$ hydrogenophosphate solution $(\mathrm{AC} / \mathrm{P})$

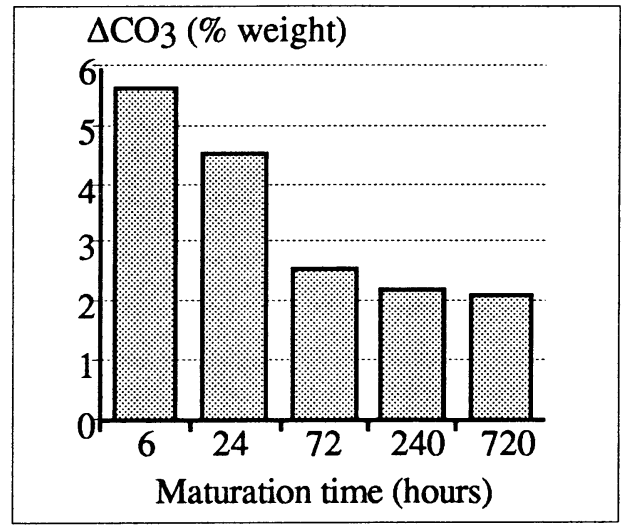

FIGURE 3: Exchange capacity of poorly crystalline carbonated apatites with the maturation time: difference between the maximun content (in $\mathrm{HCO}_{3}$ solution) and the minimun content (in $\mathrm{HPO}_{4}$ solution)

\section{DISCUSSION}

The reactivity of poorly crystalline apatites is determined in great part by their content of labile, non-apatitic environments. Freshly precipitated apatites, rich in labile non-apatitic environments exhibit the greatest reactivity ${ }^{1}$. The large difference in the dissolution enthalpies points out the very different nature of freshly precipitated and mature apatites. The composition of poorly crystalline apatites appears to be essentially determined by the maturation conditions and not by the precipitation conditions. Thus, all freshly precipitated apatites have very similar chemical compositions with a high content of $\mathrm{HPO}_{4}$ ions in non-apatitic environment and a low carbonate content. As maturation proceeds the amount of non-apatitic environments diminishes and the ability to further evolve decreases. From the available in vivo data ${ }^{1-4}$, these phenomena are also very likely to occur in vivo and might explain the changes in the composition of bone mineral which occur with aging of the crystals: newly deposited bone mineral always contains a very high content of labile non-apatitic environments and a low concentration of total carbonate ions. In older animals the mineral becomes progressively more enriched in carbonate ions and the content of labile non-apatitic environment diminishes. This behavior may be attributed, in part, to the decrease rate of bone turnover with age which allows mineral to mature in the tissue for longer periods of time.

Non-apatitic carbonate and $\mathrm{HPO}_{4}$ can be very easily and reversibly exchanged. These non-apatitic groups probably share the same surface sites on the crystals, the occupancy of which is mainly determined by an equilibrium with the solution phase. Surface groups in bone mineral can also be easily exchanged ${ }^{5}$. However, the low surface 
reactivity of the matured bone mineral may impair its biological function, especially its ability to exchange with ions of the adjacent extracellular fluid. It may also modify the surface properties and the ability of the crystals to bind proteins and other organic constituents.

The description of labile non-apatitic environments only as surface groups is not yet satisfactory as the number of non-apatitic environments in apatites is not proportional to the specific surface area or the crystal size. Thus carbonated apatites with have the same specific surface area when equilibrated in the same solutions may contain very different concentrations of labile groups, for a given surface area, depending on the length of time the crystals have matured (Table 2) and the short-range order and organization of the crystals. Thus the content of labile species is determined by both the short range order and organization and the specific surface area of the crystals.

TABLE 2

Evolution of specific surface area (SSA) and non-apatitic HPO4 groups (IR band ratio)

\begin{tabular}{lccccc}
\hline Maturation time & 6 hours & 24 hours & 72 hours & 10 days & 1 month \\
SSA $\left(\mathrm{m}^{2} \cdot \mathrm{g}^{-1}\right)$ & 165 & 185 & 178 & 173 & 190 \\
Non-A HPO4 & 0,244 & 0,232 & 0,182 & 0,173 & 0,152
\end{tabular}

\section{CONCLUSION}

Poorly crystalline apatites may be described as consisting of stable, mature apatite domains and unstable domains rich in labile non-apatitic environments of carbonate and phosphate ions. Such crystals have a highly reactive surface with non-apatitic carbonate and $\mathrm{HPO}_{4}$ groups which are easily and reversibly exchangeable. The number of such labile and rapidly exchangeable groups depends on the surface specific area and the stage of maturation of the crystals. These properties and characteristics significantly alter the interaction properties of the crystals and thus their reactivity, and thus determine not only the structure of bone mineral, but also most importantly, their biological function.

\section{REFERENCES}

1 C.Rey, B. Collins, M. Shimizu, M.J. Glimcher, Calcif. Tissue Int. 46, 384, 1990

2 A.Bencherifa, M. Jemal, Ann. Chim. Fr. 10, 543, 1985

3 Y.Wu, M.J. Glimcher, C. Rey, J. Ackerman, J. Mol. Biol.. 244, 423 (1994)

4 C. Rey, B. Collins, T. Goehl, R.I. Dickson, M.J. Glimcher, Calcif. Tissue Int.. 45.157, (1989)

5 J.T. Triffitt, A.R. Terepka, W.F. Neuman, Calcif. Tissue Res. $2.165,1968$ 